\section{REFERENCES AND NOTES}

1. X. Zhuang, Y. Mai, D. Wu. F. Zhang, X. Feng, Adv. Mater. 27 403-427 (2015).

2. C. E. Boott, A. Nazemi, I. Manners, Angew. Chem. Int. Ed. Engl. 54, 13876-13894 (2015)

3. Y. Mai, A. Eisenberg, Chem. Soc. Rev. 41, 5969-5985 (2012).

4. F. H. Schacher, P. A. Rupar, I. Manners, Angew. Chem. Int. Ed. Engl. 51, 7898-7921 (2012)

5. X. Wang et al., Science 317, 644-647 (2007)

6. J. B. Gilroy et al., Nat. Chem. 2, 566-570 (2010).

7. H. Cui, Z. Chen, S. Zhong, K. L. Wooley, D. J. Pochan, Science 317, 647-650 (2007).

8. A. H. Gröschel et al., Nature 503, 247-251 (2013).

9. T. Gädt, N. S. leong, G. Cambridge, M. A. Winnik, I. Manners, Nat. Mater. 8, 144-150 (2009)

10. H. Qiu, Z. M. Hudson, M. A. Winnik, I. Manners, Science 347 , 1329-1332 (2015)

11. J. Zhu et al., Nat. Commun. 4, 2297 (2013).

12. D. B. Wright et al., Macromolecules 48, 6516-6522 (2015).

13. G. Rizis, T. G. M. van de Ven, A. Eisenberg, Angew. Chem. Int. Ed. Engl. 53, 9000-9003 (2014)

14. B. Li, C. Y. Li, J. Am. Chem. Soc. 129, 12-13 (2007).

15. B. Dong, T. Zhou, H. Zhang, C. Y. Li, ACS Nano 7, 5192-5198 (2013).

16. B. Yu, X. Jiang, J. Yin, Macromolecules 47, 4761-4768 (2014).

17. W. Y. Chen et al., Macromolecules 37, 5292-5299 (2004).

18. J. X. Zheng et al., Macromolecules 39, 641-650 (2006).

19. Z. M. Hudson et al., Nat. Chem. 6, 893-898 (2014).

20. R. K. O'Reilly, C. J. Hawker, K. L. Wooley, Chem. Soc. Rev. 35 , 1068-1083 (2006).

21. P. A. Rupar, L. Chabanne, M. A. Winnik, I. Manners, Science 337, 559-562 (2012).

22. H. Qiu, V. A. Du, M. A. Winnik, I. Manners, J. Am. Chem. Soc. 135, 17739-17742 (2013)

23. J. P. Hill et al., Science 304, 1481-1483 (2004).

24. D. J. Pochan et al., Science 306, 94-97 (2004).

25. Z. Huang et al., Science 337, 1521-1526 (2012).

26. K. Baek, I. Hwang, I. Roy, D. Shetty, K. Kim, Acc. Chem. Res. 48, 2221-2229 (2015).

27. Z. M. Hudson, D. J. Lunn, M. A. Winnik, I. Manners, Nat. Commun. 5, 3372 (2014)

28. L. Jia et al., Nat. Commun. 5, 3882 (2014)

29. J. Qian et al., J. Am. Chem. Soc. 136, 4121-4124 (2014)

30. J. Schmelz, A. E. Schedl, C. Steinlein, I. Manners, H. Schmalz, J. Am. Chem. Soc. 134, 14217-14225 (2012)

31. L. Sun et al., Nat. Commun. 5, 5746 (2014).

\section{ACKNOWLEDGMENTS}

H.O. acknowledges a European Union Marie Curie Postdoctoral Fellowship. H.Q and Y.G. thank the European Research Council for support, and I.M. acknowledges an Advanced Investigator Grant. C.E.B. thanks the Engineering and Physical Sciences Research Council (EPSRC)-funded Bristol Chemical Synthesis Centre for Doctoral Training, O.E.C.G. thanks the EPSRC-funded Bristol Center for Functional Nanomaterials, and M.A.W. thanks the Natural Sciences and Engineering Research Council of Canada. For assistance, the authors thank V. A. Du (polymer synthesis) and J. A. Jones of the Electron Microscopy Unit (School of Chemistry, TEM) and Wolfson Bioimaging Facility (CLSM) at Bristol. PeakForce AFM was carried out in the Chemical Imaging Facility at Bristol, and SIM imaging was performed at Harwell, using equipment funded by EPSRC and the Medical Research Council, respectively. H.Q. and I.M. conceived the project. H.O. and Y.G. performed the self-assembly experiments. C.E.B. synthesized the fluorescent polymers. H.Q., C.E.B., and S.E.D.W. performed the CLSM and SIM imaging, and H.Q. and R.L.H. performed the AFM analysis. O.E.C.G. performed the manipulation experiments using optical tweezers and the corresponding analyses. H.Q. and I.M. prepared the manuscript with input from all the other authors. The project was supervised by I.M.

\section{SUPPLEMENTARY MATERIALS}

www.sciencemag.org/content/352/6286/697/suppl/DC1 Materials and Methods

Figs. S1 to S14

References (32-39)

26 November 2015; accepted 17 March 2016 10.1126/science.aad952

\title{
Slow slip near the trench at the Hikurangi subduction zone, New Zealand
}

\author{
Laura M. Wallace, ${ }^{1 *}$ Spahr C. Webb, ${ }^{2}$ Yoshihiro Ito, ${ }^{3}$ Kimihiro Mochizuki, ${ }^{4}$
} Ryota Hino, ${ }^{5}$ Stuart Henrys, ${ }^{6}$ Susan Y. Schwartz, ${ }^{7}$ Anne F. Sheehan ${ }^{8}$

The range of fault slip behaviors near the trench at subduction plate boundaries is critical to know, as this is where the world's largest, most damaging tsunamis are generated. Our knowledge of these behaviors has remained largely incomplete, partially due to the challenging nature of crustal deformation measurements at offshore plate boundaries. Here we present detailed seafloor deformation observations made during an offshore slow-slip event (SSE) in September and October 2014, using a network of absolute pressure gauges deployed at the Hikurangi subduction margin offshore New Zealand. These data show the distribution of vertical seafloor deformation during the SSE and reveal direct evidence for SSEs occurring close to the trench (within 2 kilometers of the seafloor), where very low temperatures and pressures exist.

0 ver the past 10 to 15 years, the increased availability of continuously operating Global Positioning System (cGPS) networks has revolutionized our ability to investigate spatiotemporal variations in tectonic deformation processes. These networks have enabled the discovery of slow-slip events (SSEs) at many of the world's subduction plate boundaries. SSEs are similar to earthquakes, as they involve rapid slip along a fault at rates faster than typical plate motion. However, unlike an earthquake, slip in a SSE takes place over weeks to years rather than seconds. The discovery of SSEs has revealed a much richer diversity of fault slip behavior at subduction zones than was originally thought to occur (1-4). In some cases, SSEs are observed to have a close temporal and spatial relation to damaging megathrust earthquakes (5-9).

To date, most detailed studies of crustal deformation in SSEs have focused on events occurring at 20 to $40 \mathrm{~km}$ depth, where they are typically observed by land-based geodetic networks (1, 2, 10-12). Although recent studies suggest that SSEs occur on the shallow portion of many offshore plate boundaries (<15 km depth) (13-19), detailed investigation of deformation during these shallow SSEs has been hampered by a lack of suitable seafloor geodetic methods (20). Delineating the trenchward extent and spatial distribution of SSEs on the shallow megathrust is critical for understanding the range of physical conditions

${ }^{1}$ University of Texas Institute for Geophysics (UTIG), Austin TX 78758, USA. ${ }^{2}$ Lamont-Doherty Earth Observatory (LDEO), Columbia University, Palisades, NY 10964, USA. ${ }^{3}$ Disaster Prevention Research Institute, Kyoto University, Kyoto, Japan ${ }^{4}$ Earthquake Research Institute, University of Tokyo, Tokyo, Japan. ${ }^{5}$ Department of Geophysics, Tohoku University, Sendai, Japan. ${ }^{6}$ GNS Science, Lower Hutt, New Zealand. 'Department of Earth and Planetary Sciences, University of California-Santa Cruz, Santa Cruz, CA 95064, USA. ${ }^{8}$ Cooperative Institute for Research in Environmental Sciences, University of Colorado-Boulder, Boulder, CO 80309, USA.

*Corresponding author. Email: Iwallace@utexas.edu that are conducive to slow-slip behavior. Moreover, the unexpectedly large ( $>50 \mathrm{~m})$ coseismic slip observed near the trench in the 2011 moment magnitude $\left(M_{\mathrm{w}}\right)$ 9.0 Tohoku-Oki earthquake and tsunami $(21,22)$ underscores the need to comprehend the spectrum of fault slip behavior occurring on the shallowest portion of the subduction megathrust, where tsunamigenic earthquakes occur.

One promising tool that can be used to investigate vertical deformation of the seafloor during transient deformation events is the absolute pressure gauge (APG) $(6,20,23-25)$. APGs can be deployed on the seafloor and will continuously record changes in pressure exerted on the seafloor by the overlying water column. If the seafloor rises vertically during a SSE, this will be recorded as a pressure decrease (decreasing water depth); downward movement of the seafloor will be recorded as a pressure increase (increasing water depth). APGs have documented large vertical deformation (tens of centimeters to meters) during volcanic unrest events at Axial Seamount (24). Two previous studies have shown likely vertical deformation due to slow slip at subduction zones offshore Costa Rica (25) and Japan (6), although these studies were based on data from only a few (two to four) APGs, making it impossible to define the spatial distribution of offshore deformation and slow slip. The Costa Rica study (25) shows the first convincing evidence for slow slip near the trench, based on formation and seafloor pressurechange data from two Integrated Ocean Drilling Program borehole observatories near the Middle America Trench just after periods of tremor and slow slip observed at onshore cGPS sites. Here, we present the first-ever detailed investigation of seafloor deformation above a shallow subduction interface SSE, using a network of APGs at the Hikurangi subduction zone offshore New Zealand (Fig. 1).

The Pacific Plate subducts westward beneath the eastern North Island of New Zealand along 


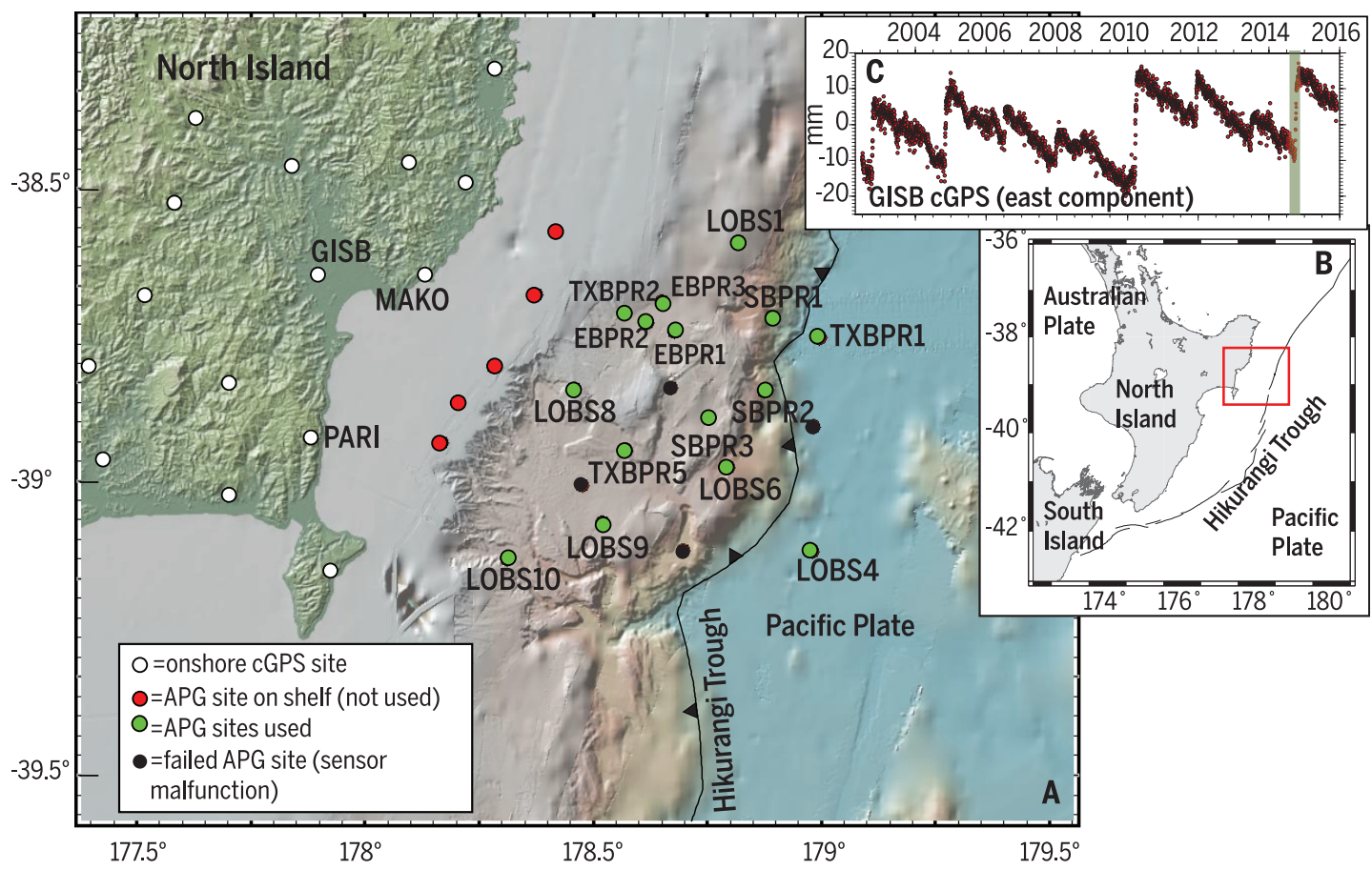

Fig. 1. Tectonic setting and HOBITSS network. (A) Tectonic setting of the northern Hikurangi margin and distribution of HOBITSS APG sites and the onshore continuous GPS network (www.geonet.org.nz). We used sites TXBPR1 and LOBS4 on the subducting Pacific Plate as references to remove oceanographic noise from the remaining network. The GPS sites we discuss in the text (GISB, MAKO, and PARI) are shown here, as are the APGs (Fig. 2). (B) Regional map of New Zealand. The red square indicates the location of (A). (C) East component of cGPS time series from GISB. Eastward (positive) jumps denote SSEs. The shaded green bar highlights the SSE from September and October 2014.
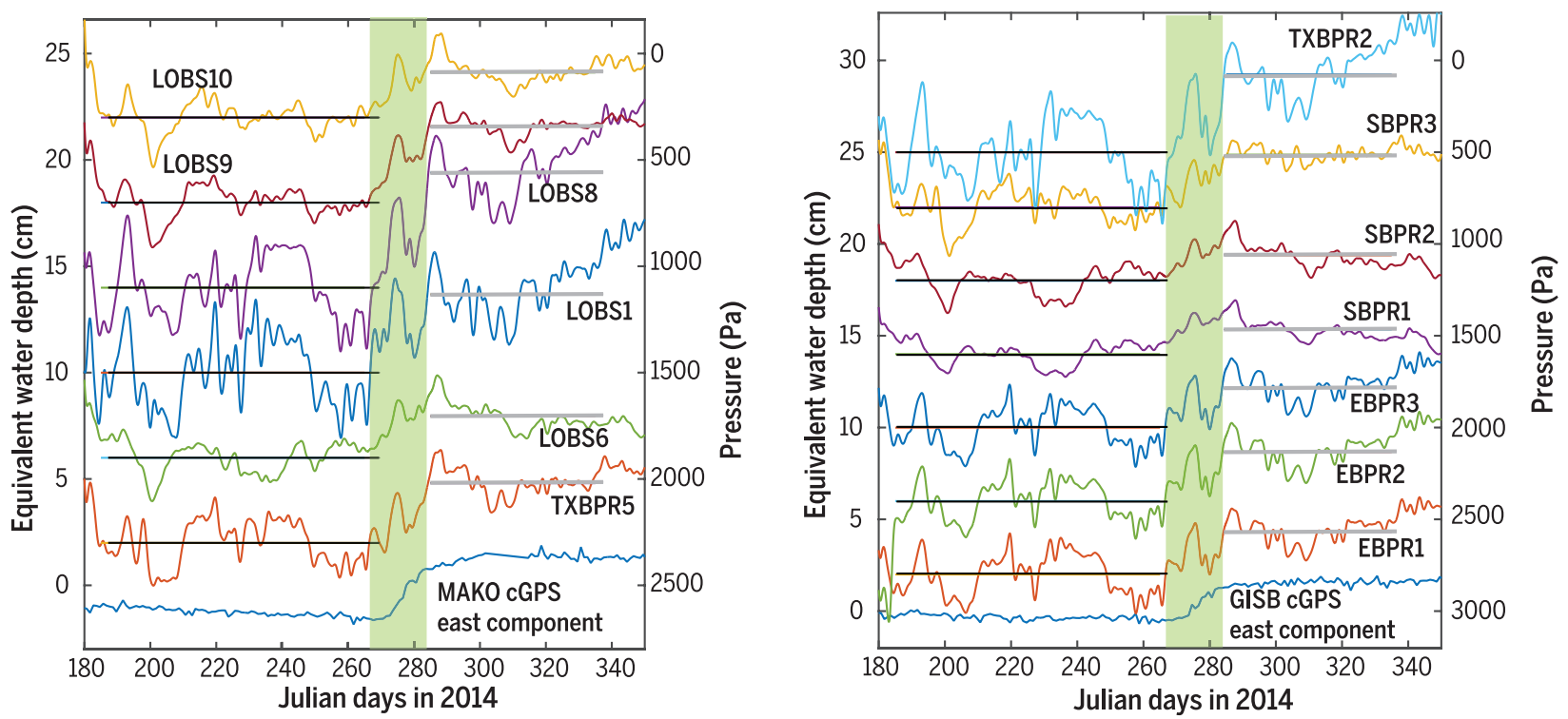

Fig. 2. cGPS (GISB and MAKO) and APG time series. The shaded green bar highlights the 2- to 3-week SSE that occurred in September and October 2014. We show APG time series in terms of pressure (Pascal) and equivalent water depth (centimeters). The values for each sensor are offset to separate each time series on the plot. We determined average seafloor pressure and equivalent water depth at each site for 3 months before the SSE (black lines) and 2 months after the SSE (gray lines). See Fig. 1 for site locations.

the Hikurangi Trough at 3 to $6 \mathrm{~cm}$ per year (26). SSEs at the northern Hikurangi margin occur offshore Gisborne, New Zealand, every 18 to 24 months (Fig. 1). These SSEs typically involve 1 to $3 \mathrm{~cm}$ of horizontal surface displacement at cGPS sites along the east coast over 1 to 2 weeks $(10,15)$ and are expected to cause much larger displacements offshore. The frequent recurrence, short duration ( $<2$ to 4 weeks), and large deformation signals make the offshore northern Hikurangi margin an ideal location to test the use of APGs to discern deformation of the seafloor during SSEs. To this end, the Hikurangi Ocean Bottom Investigation of Tremor and Slow Slip (HOBITSS) experiment began in May of 2014; this experiment involved deployment of 24. APGs and 15 ocean bottom seismometers directly above the shallow north Hikurangi SSEs. The instruments were in place 


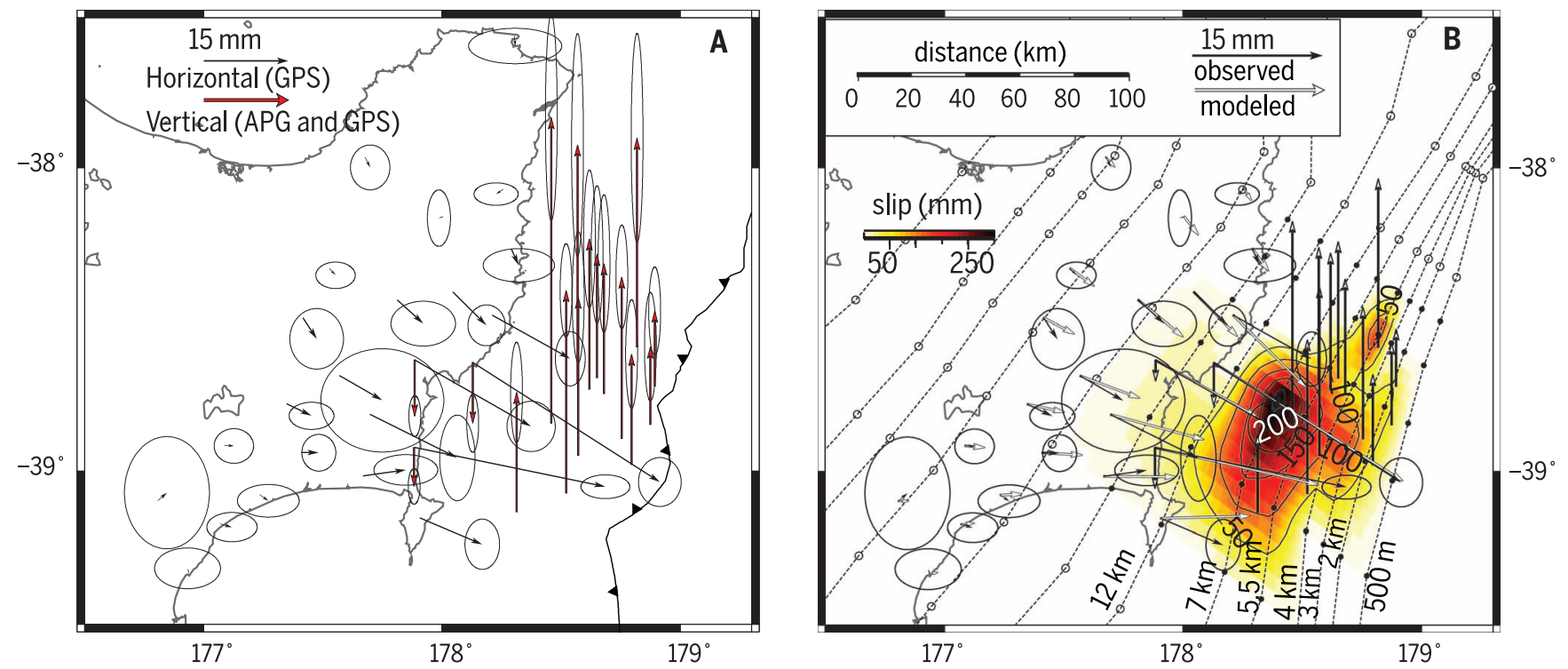

Fig. 3. Summary of surface displacements and slip inversion results for the SSE that occurred in September and October 2014. (A) Horizontal (black arrows; cGPS) and vertical displacements (red arrows; cGPS and offshore APGs) during the SSE of September and October 2014. The scale is the same for the horizontal and vertical displacements (scale bar in upper left). The deformation front is the same as in Fig. 1. (B) Inversion for slow slip from onshore and offshore surface displacements (27). The slip distribution on the interface is represented by a color gradient (see scale) and contours (labeled in millimeters). The dashed lines show the depth contours (kilometers) to the subduction interface. Note the slightly simplified deformation front used for modeling purposes.

for the duration of a large SSE that occurred beneath the HOBITSS network in September and October 2014 (Fig. 1); they were recovered in June 2015.

Seafloor pressure changes from oceanographic signals-particularly tides and eddies-are large. The largest ( 1 to $2 \mathrm{~m}$ ) diurnal and semidiurnal tidal signals are easily removed by low-pass filtering the data. The eddies offshore of the Hikurangi coast produce pressure variations that vary over spatial scales of roughly $100 \mathrm{~km}$ (27) and thus produce pressure signals that are similar over most of the HOBITTS network. This enables the use of sites on the subducting plate (where vertical deformation during SSEs will be negligible) as reference sites to remove the oceanographic noise that is common across the array. Long-term instrumental drift of the pressure gauges can also be substantial (typically several centimeters per year) (23), although the short duration $(<2$ weeks) of the North Hikurangi SSEs makes instrument drift less problematic. Our processing of the APG data to remove oceanographic noise and instrument drift is relatively simple (28) and occurs in three stages: (i) We average the values from two reference sites (LOBS-4 and TXBPR-1) on the subducting plate and subtract this from the rest of the sites in the network. (ii) To remove instrument drift, we detrend the pressure time series using the 3month period before the SSE. (iii) We apply a low-pass filter (2-day corner) to remove tidal and higher-frequency noise. Overall, we used pressure records from 13 of the 21 APG sites located on the upper plate to define the distribution of vertical deformation during the event. Five of the eight sites that we did not use were located in shallow water (less than $85 \mathrm{~m}$ depth), where

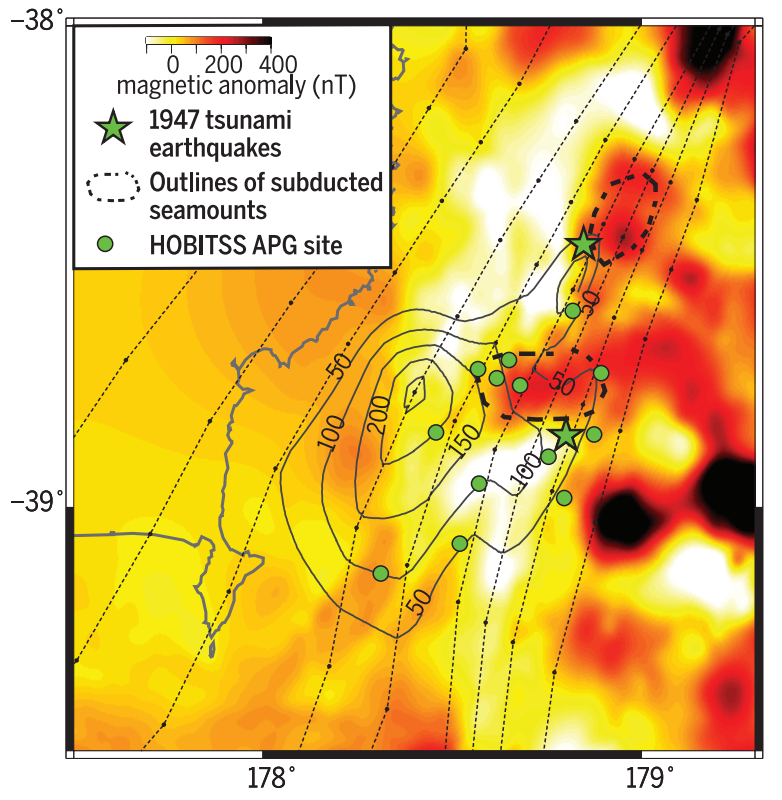

Fig. 4. Slow slip and magnetic anomalies. Magnetic anomalies (38) are shown overlain with the contours of the SSE from September and October 2014 (gray, labeled in millimeters) (Fig. 3B), the outlines of subducted seamounts (thick dashed lines), and the epicenters (green stars) of two tsunami earthquakes in March and May 1947 (39). The magnetic anomaly highs east of the trench coincide with known seamounts, whereas highs west of the trench are assumed to be subducted seamounts, which are also imaged in seismic reflection data (29).

near-coastal oceanographic signals made pressure records too noisy to reliably extract pressure changes due to a few centimeters of vertical deformation by using only deep water reference sites (green dots in Fig. 1). APGs at three of the upper-plate sites (black dots in Fig. 1) malfunctioned before the September SSE and thus did not produce usable data.

We observed a pressure decrease of 150 to $540 \mathrm{~Pa}$ (equivalent to a decrease in water depth of 1.5 to $5.4 \mathrm{~cm}$ ) at all of the upper-plate HOBITSS APG sites during the large SSE observed on nearby cGPS sites in late September and early October 2014 (Fig. 2), reflecting uplift of the upper plate above the SSE source. The temporal evolution of the pressure changes in the offshore APG time series closely tracks that of the horizontal displacements observed in the cGPS time series at nearby sites GISB and MAKO, further confirming that the pressure changes we observe in the APG data are due to vertical displacement of the seafloor during the SSE (Fig. 2). The APG time series indicates the possibility that the seafloor pressure changes begin several days before large cGPS displacements, which suggests that the SSE may have begun on the shallow interface and propagated downdip with time. To calculate the vertical displacements during the SSE, we 
calculated the difference between the average of the pressure data for the 3-month period before the SSE and the 2-month period after the SSE (Figs. 2 and 3). The uncertainties (Fig. 3A) are based on the root mean square error relative to the mean of the pressure data for the periods before and after the SSE. We chose the 3-month period before the SSE, as this was sufficiently outside the period of early rapid drift that occurs 1 to 2 months after APG deployment (23). To avoid disruption in the time series by a second SSE that occurred in December 2014, we used a 2-month period of data for the post-SSE averaging. The December SSE ruptured a patch of the interface just to the southwest of the region that ruptured in the September SSE. We find that APG sites just east (trenchward) of the shelf underwent the largest displacements (up to $5.4 \mathrm{~cm}$ ), and the magnitude of uplift tapers toward the trench, with the sites 5 to $10 \mathrm{~km}$ from the trench (SBPR1, LOBS6, SBPR2) undergoing 1.5 to $2 \mathrm{~cm}$ of uplift. Uplift of these near-trench sites indicates that large SSE slip continues onto the shallowest portions of the subduction interface close to the trench, and possibly all the way to the trench itself. The site where we observe the largest uplift signal (LOBS8) is closest to the cGPS sites recording the largest horizontal SSE displacements (MAKO, GISB, PARI) (Fig. 1), and the offshore uplift signals taper both northeast and southwest along strike, in good agreement with the pattern of onshore cGPS displacements (Fig. 3A).

We inverted the onshore cGPS displacements and vertical displacements observed in the offshore APG network to determine the distribution of shallow slow slip on the subduction interface (28). Our best-fitting slip inversion (Fig. 3B) fits both the horizontal cGPS and the vertical APG displacements to within uncertainty, with a reduced $\chi^{2}$ of 0.80 and 1.16 for the cGPS and APG data, respectively. The SSE in September and October 2014 has an equivalent moment magnitude of $M_{\mathrm{w}} 6.8$.

Our best-fitting slip model (Fig. 3B) reveals the major locus of large slip (10 to $20 \mathrm{~cm}$ ) focused between 7 and $4 \mathrm{~km}$ depth beneath the central portion of the HOBITSS network, with $\sim 10 \mathrm{~cm}$ of slip penetrating updip as shallow as $3 \mathrm{~km}$ depth in some locations. Further northeast along strike, the observed large vertical displacement $(3.7 \mathrm{~cm})$ at LOBS1 is fit well by a small patch of shallow, large slip $(\sim 10 \mathrm{~cm})$ occurring at $\sim 4 \mathrm{~km}$ below the seafloor. Our results suggest that $\sim 5 \mathrm{~cm}$ of slip penetrates to within $2 \mathrm{~km}$ of the seafloor beneath the HOBITSS network, and some slip (up to a few centimeters) might penetrate all the way to the trench. To determine the shallowest extent of slow slip required by our APG data, we conducted sensitivity tests for the updip limit of slip. These tests require a reasonable amount of slip (3 to $5 \mathrm{~cm}$ or more) to occur to within $2 \mathrm{~km}$ of the seafloor (28). An even denser network would be needed to resolve the slip distribution on the portion of the plate boundary between $2 \mathrm{~km}$ depth and the seafloor.

The shallow slow slip recorded by our APG network occurred on a portion of the plate interface that ruptured in a tsunami earthquake in March
1947 (29) (Fig. 4), which suggests that shallow SSE source areas are capable of hosting seismic rupture and tsunamigenesis. This observation has major implications for seismic and tsunami hazards at subduction zones worldwide. Tsunami earthquakes are defined as subduction thrust earthquakes located near the trench that produce a larger-than-expected tsunami for the earthquake's magnitude; they typically have long source durations and lack high-frequency energy. These characteristics are often attributed to similar transitional frictional conditions (30) thought to exist in shallow SSE source areas (18). Seismic reflection and magnetic data suggest the presence of a subducted seamount in the area of the March 1947 earthquake; rupture over this seamount is thought to have increased tsunami excitation (29). There is an apparent gap of large $(>10-\mathrm{cm})$ slow slip in our best-fitting SSE model where the seamount collides with the subduction interface (Fig. 4), suggesting that the properties of the subduction interface in the region of seamount subduction may be less conducive to slow slip. If the seamount does act as a barrier to slow slip, two potential explanations are: (i) the region of the interface struck by the seamount may be interseismically locked (velocity weakening) and may host nucleation of earthquakes similar to the 1947 earthquake (29) or (ii) the portion of the fault affected by seamount subduction possesses velocity-strengthening behavior and creeps steadily. Answering this question remains at the heart of a debate over the role that subducting seamounts play in subduction interface seismogenesis (31-33).

The HOBITSS APG results provide the first detailed view of seafloor deformation during a shallow, offshore SSE and open a frontier for high-resolution, near-field investigations of shallow SSEs and other similarly sized transient deformation events at offshore plate boundaries. These data demonstrate that large SSEs can occur on the shallowest reaches of the subduction megathrust, where very low temperatures and pressures exist. Our result of slow slip near the trench suggests that conditionally stable or velocityweakening frictional conditions exist on a portion of the interface traditionally thought to be dominated by steady creep (velocity strengthening). There is also evidence for shallow SSEs on continental faults $(34,35)$. Similar physical mechanisms are probably behind shallow SSEs in continental versus subduction settings, but we expect that fluids may play a larger role in shallow SSEs at subduction zones. Our observations and those from Costa Rica $(25,36)$ raise the likelihood that shallow SSEs observed at other subduction zones $(14,17,18,37)$ may involve large slip to the trench. Seafloor geodetic investigations at these subduction zones and elsewhere are needed to discern the role that SSEs play globally in the accommodation of plate motion on the shallowest portion of the megathrust.

\section{REFERENCES AND NOTES}

1. G. Dragert, K. Wang, T. S. James, Science 292, 1525-1528 (2001)

2. K. Obara, H. Hirose, F. Yamamizu, K. Kasahara, Geophys. Res. Lett. 31, L23602 (2004)
3. S. Schwartz, J. Rokosky, Rev. Geophys. 45, RG3004 (2007).

4. S. Ide, G. C. Beroza, D. R. Shelly, T. Uchide, Nature 447, 76-79 (2007)

5. A. Kato et al., Science $335,705-708$ (2012)

6. Y. Ito et al., Tectonophysics $600,14-26$ (2013)

7. S. Ruiz et al., Science 345, 1165-1169 (2014).

8. S. Graham et al., Geophys. J. Int. 197, 1593-1607 (2014).

9. N. Uchida, T. linuma, R. M. Nadeau, R. Bürgmann, R. Hino, Science 351, 488-492 (2016).

10. L. M. Wallace, J. Beavan, J. Geophys. Res. 115, B12402 (2010).

11. N. M. Bartlow, S. Miyazaki, A. M. Bradley, P. Segall, Geophys. Res. Lett. 38, L18309 (2011)

12. M. Radiguet et al., J. Geophys. Res. 117, B04305 (2012).

13. A. Douglas, J. Beavan, L. M. Wallace, J. Townend, Geophys. Res. Lett. 32, L16305 (2005).

14. S. Ozawa, H. Suito, M. Tobita, Earth Planets Space 59 , 1241-1245 (2007)

15. L. M. Wallace, J. Beavan, S. Bannister, C. Williams, J. Geophys. Res. 117, B11402 (2012)

16. T. H. Dixon et al., Proc. Natl. Acad. Sci. U.S.A. 111 17039-17044 (2014)

17. M. Valée et al., J. Geophys. Res. 118, 2965-2981 (2013).

18. D. Saffer, L. M. Wallace, Nat. Geosci. 8, 594-600 (2015).

19. Y. Yamashita et al., Science 348, 676-679 (2015).

20. R. Bürgmann, D. Chadwell, Annu. Rev. Earth Planet. Sci. 42 509-534 (2014)

21. T. linuma et al., J. Geophys. Res. 117, B07409 (2012).

22. S. Kodaira et al., Nat. Geosci. 5, 646-650 (2012).

23. A. Polster, M. Fabien, H. Villinger, Geochem. Geophys. Geosyst. 10, Q08008 (2009)

24. W. Chadwick, S. Nooner, D. Butterfield, M. Lilley, Nat. Geosci. 5 , 474-477 (2012)

25. E. Davis, H. Villinger, T. Sun, Earth Planet. Sci. Lett. 410 , 117-127 (2015)

26. L. M. Wallace, J. Beavan, R. McCaffrey, D. Darby, J. Geophys. Res. 109, B12406 (2004)

27. S. M. Chiswell, N. Z. J. Mar. Freshw. Res. 39, 121-134 (2005).

28. Supplementary materials are available on Science Online.

29. R. Bell, C. Holden, W. Power, X. Wang, G. Downes, Earth Planet. Sci. Lett. 397, 1-9 (2014)

30. S. Bilek, T. Lay, Geophys. Res. Lett. 29, 1673 (2002).

31. C. Scholz, C. Small, Geology 25, 487-490 (1997).

32. K. Mochizuki, T. Yamada, M. Shinohara, Y. Yamanaka, T. Kanazawa, Science 321, 1194-1197 (2008).

33. K. Wang, S. Bilek, Geology 39, 819-822 (2011).

34. J. R. Murray, P. Segall, J. Geophys. Res. 110, B09407 (2005).

35. R. Jolivet et al., Earth Planet. Sci. Lett. 377-378, 23-33 (2013)

36. E. Davis, M. Heesemann, K. Wang, Earth Planet. Sci. Lett. 306 299-305 (2011)

37. T. Nishimura, Prog. Earth Planet. Sci. 1, 22 (2014).

38. R. Sutherland, Geophysical Map 9: Magnetic anomalies in the New Zealand region (Institute of Geological and Nuclear Sciences, 1996)

39. D. I. Doser, T. H. Webb, Geophys. J. Int. 152, 795-832 (2003)

\section{ACKNOWLEDGMENTS}

We acknowledge support from U.S. NSF grants OCE-1334654 1333311,1332875 , and 1333025 to L.M.W., S.C.W., S.Y.S., and A.F.S. and Japan Society for the Promotion of Science grant KAKENHI-26257206 to Y.I. Raw data from the experiment are archived at the Incorporated Research Institutions for Seismology Data Management Center. Additional funding support came from Japan's Ministry of Education, Culture, Sports, Science and Technology; the University of Tokyo Earthquake Research Institute: and the International Research Institute of Disaster Science at Tohoku University. Support for ship time was provided by NSF, GNS Science, and Land Information New Zealand's Oceans 2020 program. We greatly appreciate the immense contribution to the success of this project from ocean bottom instrument engineering teams at LDEO, UTIG, University of Tokyo, and Tohoku University, as well as the captain and crew of the U.S. R/V Roger Revelle and New Zealand R/V Tangaroa.

\section{SUPPLEMENTARY MATERIALS}

www.sciencemag.org/content/352/6286/701/suppl/DC1

Materials and Methods

Supplementary Text

Figs. S1 to S4

Tables S1 and S2

References (40-46)

11 January 2016; accepted 25 March 2016

$10.1126 /$ science.aaf2349 


\section{Science MIAAAS}

Slow slip near the trench at the Hikurangi subduction zone, New Zealand

Laura M. Wallace, Spahr C. Webb, Yoshihiro Ito, Kimihiro

Mochizuki, Ryota Hino, Stuart Henrys, Susan Y. Schwartz and

Anne F. Sheehan (May 5, 2016)

Science 352 (6286), 701-704. [doi: 10.1126/science.aaf2349]

Editor's Summary

\section{Applying pressure to plate tectonics}

The full range of deformation behavior of subduction zone faults that are responsible for great earthquakes and tsunamis is now clearer. Wallace et al. observed the heave of the ocean floor near the Hikurangi trench, off the east coast of New Zealand, with a network of absolute pressure gauges (see the Perspective by Tréhu). The gauges sit on the ocean floor and detect changes in pressure generated from slow-slip deformation events. Detailed geodetic observation of deformation events will finally clarify the role that such aseismic events play at major plate boundaries.

Science, this issue p. 701; see also p. 654

This copy is for your personal, non-commercial use only.

Article Tools Visit the online version of this article to access the personalization and article tools:

http://science.sciencemag.org/content/352/6286/701

Permissions Obtain information about reproducing this article: http://www.sciencemag.org/about/permissions.dtl

Science (print ISSN 0036-8075; online ISSN 1095-9203) is published weekly, except the last week in December, by the American Association for the Advancement of Science, 1200 New York Avenue NW, Washington, DC 20005. Copyright 2016 by the American Association for the Advancement of Science; all rights reserved. The title Science is a registered trademark of AAAS. 